\title{
La educación especial e inclusiva desde la educación popular
}

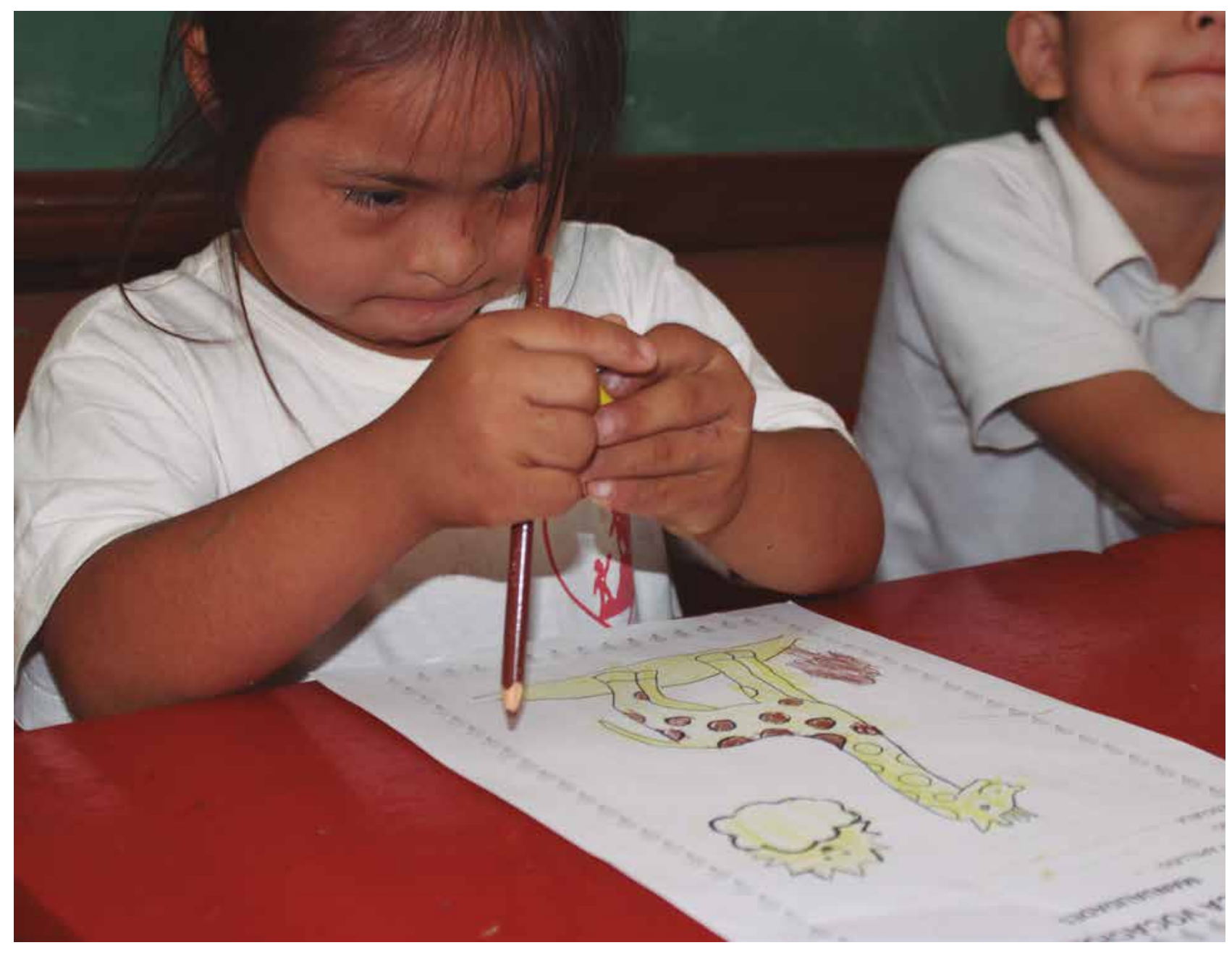

El presente artículo comparte la experiencia de Fe y Alegría en la educación especial y la educación inclusiva en Bolivia, desde una mirada de educación popular, sus principios y metodología, resaltando la importancia de un rol más activo de los padres y madres de familia en participar y acompañar el desarrollo de las diferentes etapas

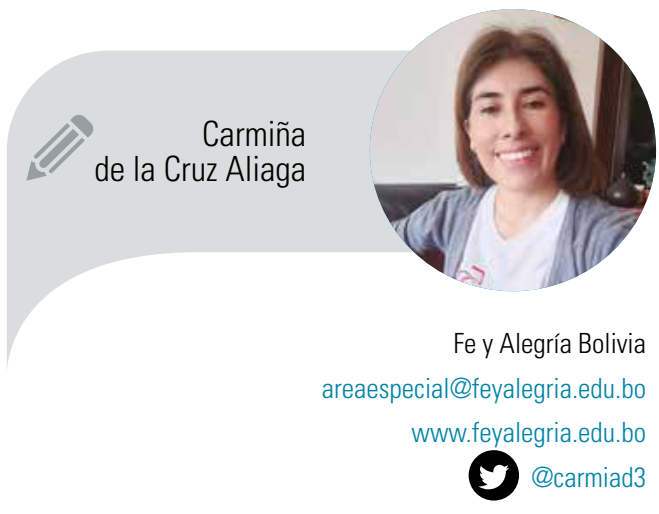
de sus hijos e hijas con discapacidad, para lograr el ejercicio de su ciudadanía y participación plena en la sociedad. 


\section{Situación de las Personas con Discapacidad en Bolivia}

Históricamente las personas con discapacidad han sido las más excluidas de la sociedad, negándoseles tanto el ejercicio de sus derechos básicos y fundamentales como su participación. Más de mil millones de personas tienen alguna discapacidad en el mundo, lo que representa el $15 \%$ de la población.

Según el último censo de población y vivienda del año 2012, en Bolivia 388109 personas tienen algún tipo de discapacidad. Este número va en aumento, debido al envejecimiento de la población, siendo las personas mayores las más expuestas a adquirir alguna discapacidad; debido al incremento de enfermedades crónicas, de las asociadas a factores ambientales $u$ a otros factores como los accidentes de tránsito, catástrofes naturales, etc.

En los últimos 15 años, Bolivia ha avanzado en cuanto al marco normativo en materia de discapacidad, desde la Constitución Política del Estado el año 2009 mediante Ley N. ${ }^{\circ}$ 4024, se compromete a "promover, asegurar y proteger el goce pleno y en condiciones de igualdad todos los derechos humanos, libertades fundamentales y el respeto a su dignidad inherente de las PcD" establecidos en la Convención Internacional de los Derechos de las Personas con Discapacidad.

El Sistema Educativo Plurinacional se organiza en tres subsistemas, uno de ellos, el Subsistema de Educación Alternativa y Especial, se desarrolla en el marco de los enfoques de la educación popular, comunitaria e inclusiva y la educación a lo largo de la vida.

El subsistema de educación especial con enfoque de educación inclusiva es la respuesta educativa a estudiantes con discapacidad, con dificultades de aprendizaje y con talento extraordinario, cuya atención puede darse de forma directa en los mismos centros de educación especial y de forma indirecta apoyando los procesos de educación inclusiva en unidades educativas regulares o centros de formación técnica productiva.

En Bolivia existen alrededor de 122 centros de educación especial que pertenecen al Estado, algunos de ellos son de convenio como los centros de Fe y Alegría, que llegarían a cubrir el $6 \%$ de la cobertura nacional.
Situación de las

Personas con Discapacidad en Bolivia

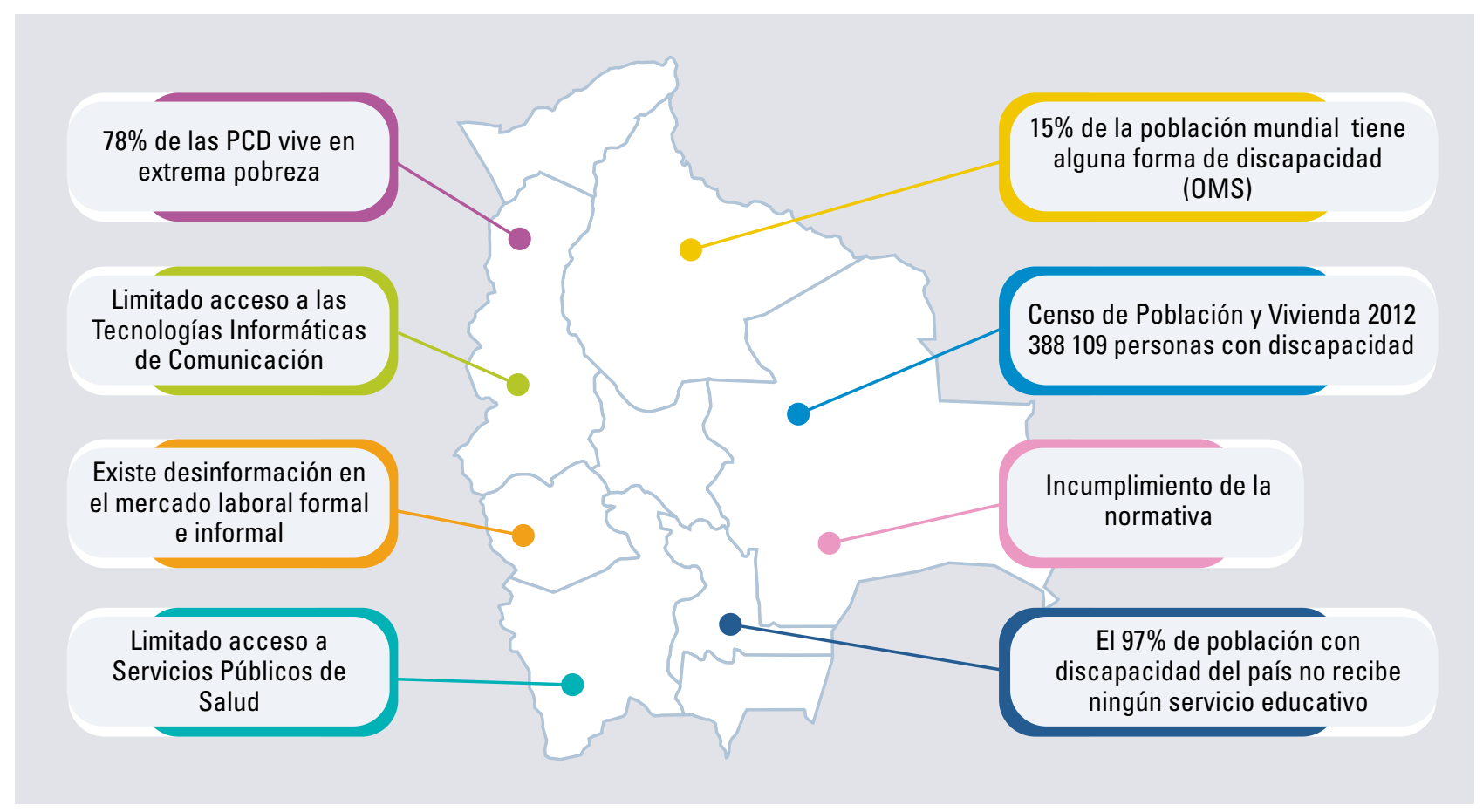




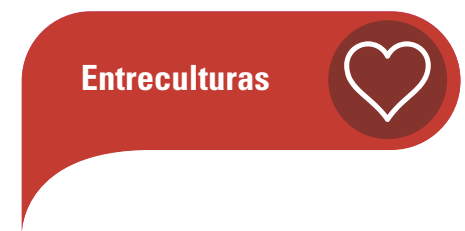

\section{Actual Ley Educativa 070}

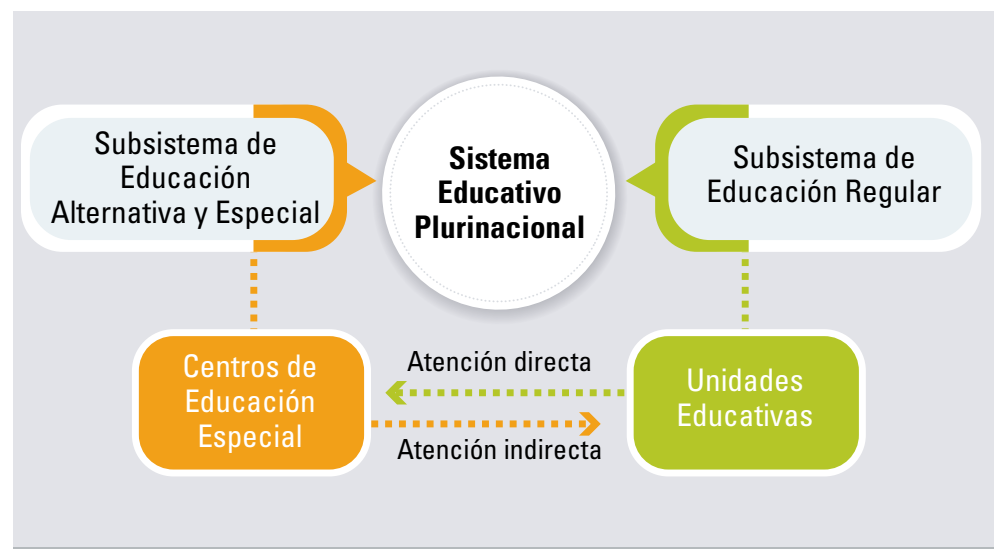

La realidad es que en Bolivia el 97\% de la población con discapacidad no recibe ningún servicio educativo. Por lo tanto, los niños y niñas con discapacidad tienen menos oportunidades educativas, menos probabilidades de escolarizarse, mayores dificultades de permanecer en ella y superar los cursos sucesivos. Existe menos posibilidad de concluir la primaria básica en comparación a la población sin discapacidad.

Esto evidencia el poco avance en el acceso a la educación más enfocada a la educación básica de la población con discapacidad, sin visibilizar su tránsito a la educación secundaria y superior donde no se cuenta con datos específicos y offciales de su avance. Finalmente, el 97\% de la población vive en extrema pobreza. Por lo tanto, pese a contar con una normativa que favorece, se visualiza muy poco avance real y de participación de las personas con discapacidad.

Con la pandemia de la COVID-19, esta realidad se ha agudizado debido a lo poco que se ha avanzado en materia educativa, porque ha limitado el acceso y participación de nuestros estudiantes con discapacidad a la educación virtual, sea en la educación especial o en centros inclusivos. Por un lado, por la falta de conectividad en sus hogares, el alto costo de internet, muchos de los estudiantes con discapacidad no cuentan con equipos para poder acceder y participar de las clases virtuales porque muchos son de familias de escasos recursos económicos; y por otro, el limitado apoyo de las familias porque trabajan o "viven al día", que es una realidad que se enfrenta para lograr el apoyo y participación de las familias. Sin duda, la no presencialidad ha limitado el desarrollo personal y social de los y las estudiantes con discapacidad por la falta de contacto con sus educadores, educadoras y compañeros, compañeras de aula y por ende ha reducido su participación social.

\section{El camino de Fe y Alegría a la educación inclusiva desde una mirada de educación popular}

Fe y Alegría en su permanente compromiso de llegar con la educación, como herramienta de transformacióna los sectores más excluidos desde la educación popular, puso en marcha el área de Educación Especial hace más de 30 años. Y lo hizo con la creación y fundación de sus centros de educación especial. Esto fue posible gracias a la iniciativa de personas amigas y familiares que, comprometidas con sus hijos e hijas con discapacidad, buscaron el acceso a la educación. Fe y Alegría se convirtió en ese entonces en la única respuesta educativa a las necesidades de la población con discapacidad hasta ese momento invisibilizada.

Gracias al trabajo comunitario y participativo que realiza Fe y Alegría en sus centros educativos, buscando impulsar esa educación humanizadora que permita el acceso igualitario a la educación, es que se empieza a abrir la escolarización de niños y niñas con discapacidad en las escuelas regulares, cuestionando como única respuesta educativa los centros de educación especial y ampliando en otras modalidades educativas.

Desde Fe y Alegría hay una apuesta clara por la educación inclusiva con el objetivo de ampliar las oportunidades educativas de las personas con discapacidad. Estos principios van en consonancia con la educación popular:

$\boldsymbol{\lambda}$ Defiende y propone el acceso igualitario a la educación para todos y todas, garantizando los derechos humanos y la participación de toda la comunidad educativa, trabajando con y por los más excluidos. 


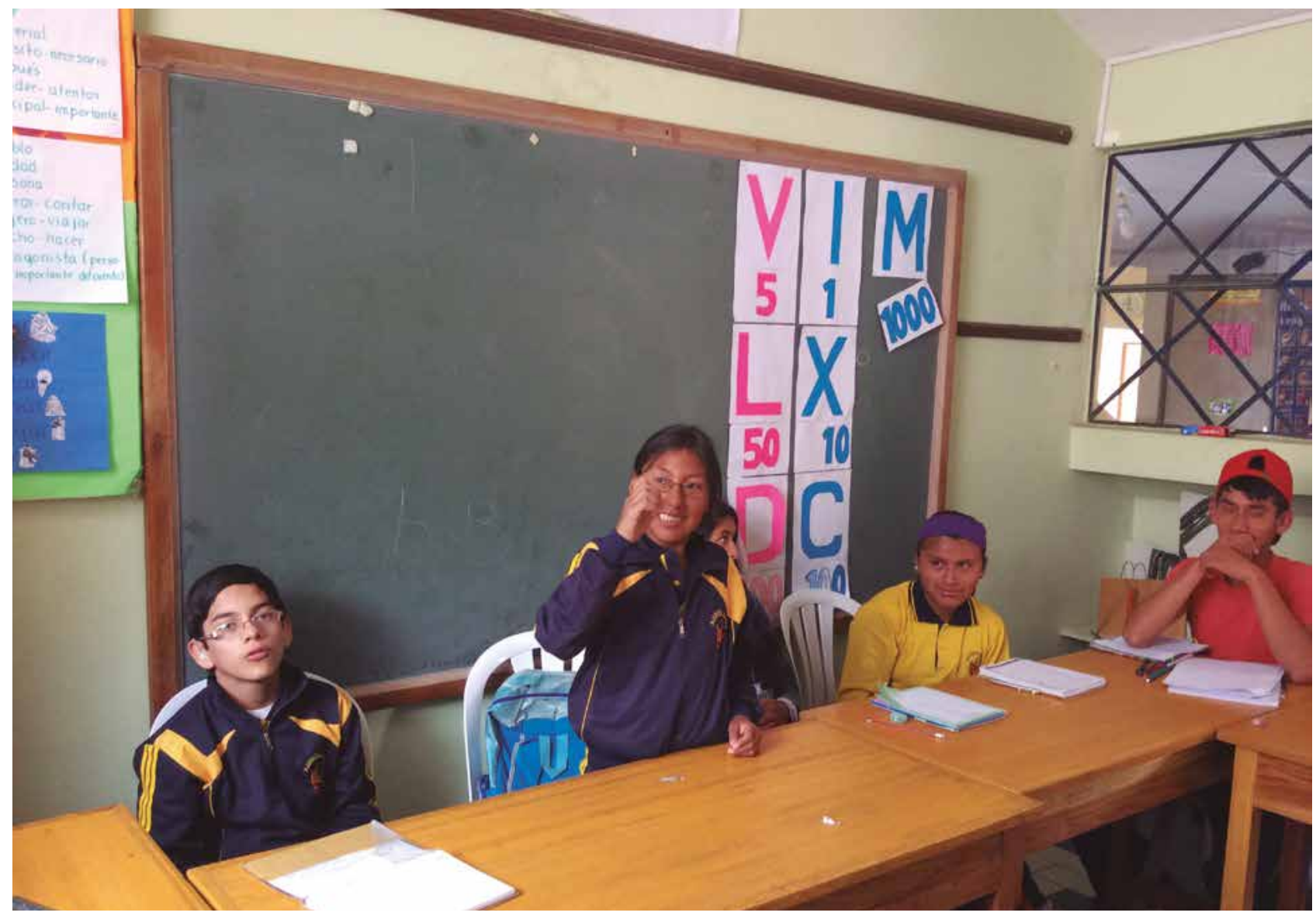

入 Desde el conocimiento de su realidad y de sus contextos para identificar $y$ reflexionar sobre sus necesidades, expectativas y posibilidades de generar apoyos.

入 Valora y aprende de la diversidad humana, como un aprendizaje permanente por responder a las necesidades de todos y todas.

入 Promueve la formación de educadores y la generación de prácticas pedagógicas innovadoras para responder a las necesidades educativas de los estudiantes.

$\boldsymbol{\lambda}$ Construye el empoderamiento de los más excluidos, generando espacios de encuentro y diálogo para propiciar su organización y participación en la reivindicación y ejercicio de sus derechos.

Por tanto, desde los centros de Fe y Alegría, se apunta a una educación transformadora desde la educación popular que genere cambios en una gestión educativa de calidad con el objetivo de implementar políticas inclusivas que afecten la organización y dinamización

\section{Los niños y niñas con discapacidad tienen}

menos oportunidades educativas, menos

probabilidades de escolarizarse, mayores

dificultades de permanecer en ella y superar los

cursos sucesivos

de los centros con la participación de toda la comunidad para responder a la diversidad. Que genere espacios de formación permanente al profesorado para que desarrolle prácticas inclusivas que les permita responder a las necesidades educativas de sus estudiantes. Además de desarrollar espacios de sensibilización y concientización a la comunidad para generar una cultura inclusiva de respeto y valoración de la diversidad y el apoyo a las familias.

Todo en un ser humano y su medio ambiente afecta a la forma en que el mismo sujeto crece y se desarrolla. URIE BONFRenbenner 

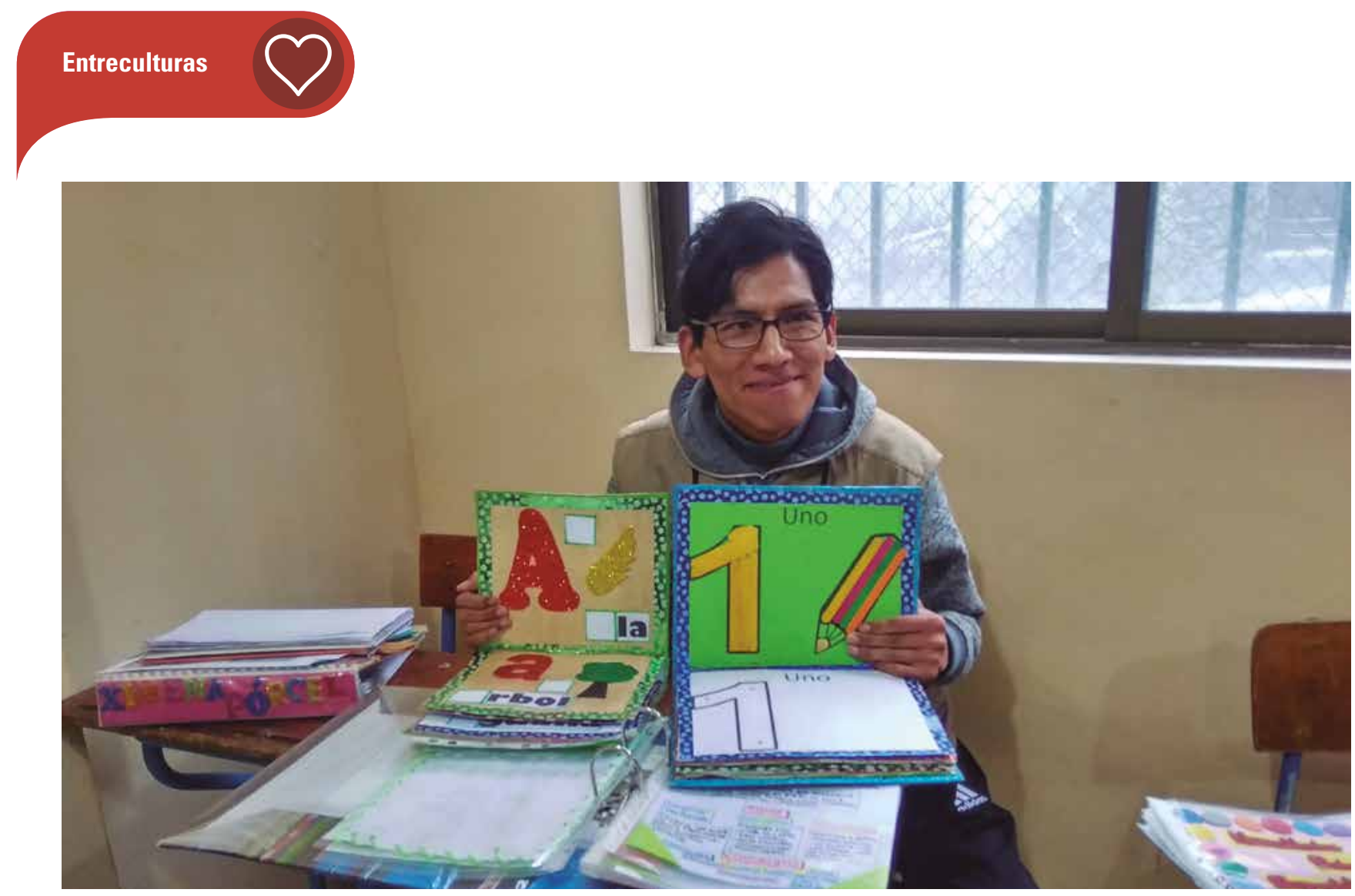

\section{Actual Ley Educativa 070}

\begin{tabular}{|c|c|c|}
\hline & $\begin{array}{l}\text { Gestión } \\
\text { educativa de } \\
\text { calidad }\end{array}$ & $\begin{array}{l}\text { Desarrollar procesos educativos de manera } \\
\text { reflexiva y planificada para responder a las } \\
\text { necesidades educativas de sus estudiantes, } \\
\text { de acuerdo a su realidad y contexto para } \\
\text { generar red de apoyos en su comunidad } \\
\text { (políticas inclusivas). }\end{array}$ \\
\hline & $\begin{array}{l}\text { Formación } \\
\text { permanente a los } \\
\text { educadores }\end{array}$ & $\begin{array}{l}\text { Brindar las herramientas teórico-prácticas } \\
\text { para responder a las necesidades educativas } \\
\text { de sus estudiantes, desarrollar prácticas } \\
\text { inclusivas. } \\
\text { - Reflexionar sobre sus prácticas inclusivas. } \\
\text { - Trabajo en equipo entre los educadores y } \\
\text { educadoras. }\end{array}$ \\
\hline & $\begin{array}{l}\text { Sensibilización / } \\
\text { concientización } \\
\text { a la comunidad }\end{array}$ & $\begin{array}{l}\text { - Generar y promover una cultura inclusiva de } \\
\text { respeto, cooperación y valoración a la } \\
\text { diversidad. } \\
\text { - Trabajo de apoyo con las familias. }\end{array}$ \\
\hline
\end{tabular}

\section{La importancia de la} participación de la familia desde un enfoque ecológico funcional

Desde la experiencia en Fe y Alegría nos encontramos que nuestros y nuestras estudiantes con discapacidad tienen un rol pasivo en la familia, al ser tratados como un o una "eterna niña" a la que hay que cuidar y sobreproteger, por tanto, no participan de las responsabilidades y activida- des de la familia. Pueden estar años en su centro de educación especial tratando de aprender a leer o escribir o haciendo actividades que no corresponden a su edad cronológica, haciéndose adultos y a los que no se les permite visualizar su proyecto de vida y su transición a la vida adulta. Limitando de esta manera las posibilidades de transformar sus propias vidas.

En esa búsqueda de mejorar la formación y participación de los y las estudiantes con discapacidad en nuestra sociedad, desde esa mirada humanizadora, se incorpora en el currículo de los centros de educación especial y de educación regular de Fe y Alegría y se forma a los educadores en el enfoque ecológico funcional que genera cambios en la forma de enseñar y aprender, empodera a los estudiantes con discapacidad y a sus familias, brindándoles oportunidades de aprender habilidades y destrezas significativas para la vida en los contextos más naturales como su barrio, la comunidad, de tal modo que los prepare para mejorar su calidad de vida y aumente su participación ejerciendo su ciudadanía.

Tal como lo estableció el psicólogo ruso americano Bonfrenbrenner, el enfoque ecológico funcional se centra en la persona y la relación dinámica con sus diferentes entornos de desarrollo, desde la familia, su comunidad, su escuela, su trabajo, etc., y es a partir de esta relación que la persona aprende y desarrolla habilidades que le 


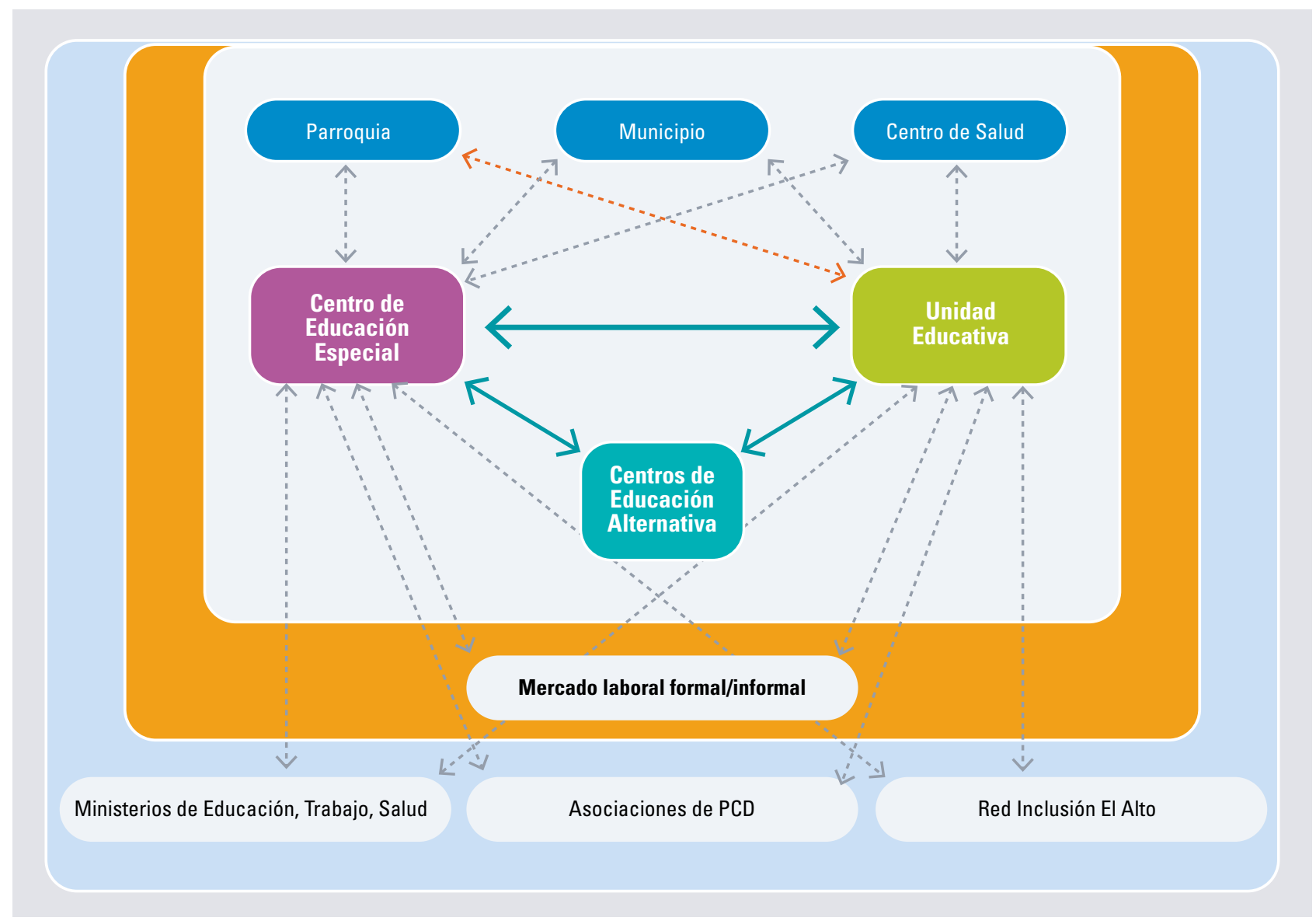

permitan desenvolverse y participar en la vida. Salimos de la escuela para enseñar a los y las estudiantes en los ámbitos donde se desarrolla naturalmente y la familia es parte del equipo junto con los educadores y educadoras, con los que se van a buscar soluciones para lograr los mejores aprendizajes para sus hijos e hijas.

Desde esa mirada, los padres y madres cumplen un rol muy importante en ese camino, son los que mejor acompañan durante toda la vida a sus hijos e hijas con discapacidad. Por ello, es necesario ser el espacio de escucha y apoyo para conocer y comprender la realidad que enfrentan las familias, las cuales viven el proceso desde el entendimiento, aceptación y adaptación al nacimiento de un hijo o hija diferente, superar el dolor de no tener un hijo sano y afrontar los prejuicios y actitudes que aún tiene la sociedad en torno a la discapacidad.

Las familias viven de manera diferente la discapacidad en cada hogar, la aceptación llega en las diferentes etapas de la vida, lo que les permite manejar la discapacidad de su hijo o hija. Las mejores relaciones están enmarcadas por el respeto

\section{Los padres y madres cumplen un rol muy importante en ese camino, son los que mejor acompañan durante toda la vida a sus hijos e hijas con discapacidad. Por ello es necesario ser el espacio de escucha y apoyo para conocer y comprender la realidad que enfrentan las familias}

mutuo y la confianza entre las familias, los educadores y los profesionales donde intercambian información e ideas sobre el cuidado, intervención médica, apoyos y programas educativos para el estudiante con discapacidad.

En conclusión, la construcción de una red de apoyo para el centro educativo y la familia es fundamental para apoyar los procesos de inclusión que permitan contar con servicios de apoyo profesional ligado al acceso a información oportuna, asesoramiento orientado a la atención de los miembros de la familia de manera individual o grupal mediante la interacción de las familias, contar con el apoyo de otros centros, viendo 


\section{(iii) caminanoo juntos}

Encuentro de Padres y Madres de familia y Jóvenes Sordos

En esa construcción de esa red de apoyo para las familias y fortalecer su liderazgo y participación, desde Fe y Alegría organizamos diferentes espacios de encuentros sobre procesos de inclusión de personas sordas, compartiendo la actividad con otra institución amiga la Fundación Machaqa, donde participaron madres, padres, abuelas y hermanos de estudiantes jóvenes sordos de nuestros centros educativos que pertenecen a las asociaciones de sordos de las diferentes regionales, para generar ese espacio de escucha intergeneracional, de impulso a las familias y a los jóvenes, mediante el diálogo y la escucha activa, donde cada uno, desde sus saberes compartieron sus vivencias y experiencias con el fin de reflexionar sobre sus realidades, sus necesidades, compartir sus expectativas y trabajar en esas propuestas para transformar y mejorar sus condiciones de vida.

Estos espacios nos permiten identificar nuevos liderazgos en los jóvenes sordos que representan a la comunidad sorda y lograr que las familias se comprometan por esa lucha permanente en la reivindicación de los derechos de sus hijos e hijas con instancias de decisión, siendo un espacio auténtico de participación democrática, en el ejercicio de esa ciudadanía que se construye día a día.

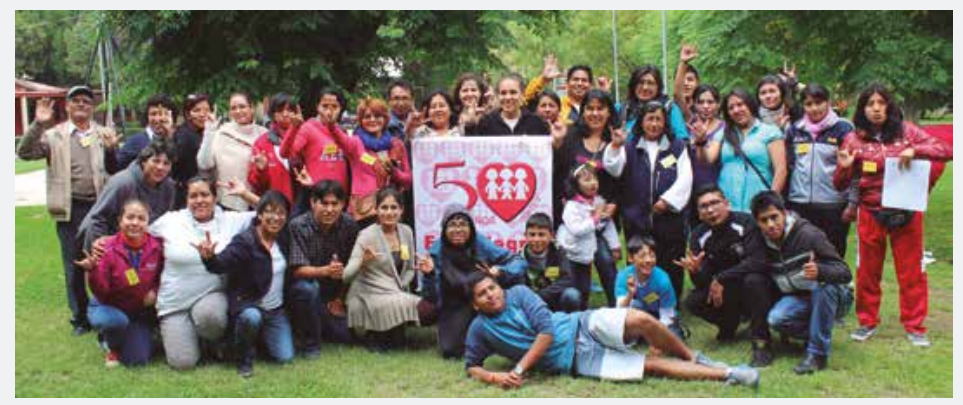

el continuo educativo y la participación en otros espacios de la sociedad.

El centro de educación especial o el centro inclusivo debe ser parte de su comunidad, se debe iniciar realizando un mapeo identificando los posibles aliados que van a facilitar el acceso a los apoyos que requiere el centro para la inclusión de

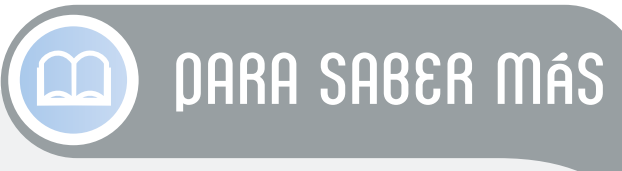

Federación Internacional de Fe y Alegría. (2013). Educación inclusiva y sus desafíos. Revista internacional Fe y Alegría, (14). https://www.feyalegria.org/wpcontent/uploads/fya-biblioteca/archivos/file/RevistaFeyAlegriaN14.pdf

GInÉ, C. (Coord.). (2010). La educación inclusiva. De la exclusión a la plena participación de todo el alumnado: Cuadernos de Educación, n.5 56. Barcelona: ICE- Horsori.

LAYNES, M. G. (2014). Guía conceptual enfoque ecológico. Federación Internacional. Programa de informática educativa.

\section{El centro de educación} especial debe ser parte de su comunidad, identificando los posibles aliados que van a facilitar el acceso a los apoyos que requiere el centro para la inclusión de sus estudiantes

sus estudiantes, por ejemplo, articularse con el centro de salud del barrio para el acceso a servicios de salud, apoyos específicos que puedan requerir de profesionales como fonoaudiólogos, psicólogos, fisioterapeutas, etc.

Esta red de apoyo debe permitir ver el futuro y el continuo educativo de los y las estudiantes una vez que finalizan su formación en los centros, viendo la transitabilidad a los centros de formación técnica, las universidades, para preparar a sus estudiantes en esa posible vía de continuidad. Y por ende mirar el contexto laboral que existe en la comunidad, es decir, qué tipo de empresas, cual es la vocación productiva del lugar que va a posibilitar pensar en esa salida laboral, que oriente en el perfil formativo que se brinda a los y las estudiantes.

Por último, no podemos olvidar que los centros son parte de una red más grande donde están las autoridades de su comunidad, las redes interinstitucionales que trabajan en el tema educativo y defensa de los derechos que pueden permitir incidir y generar cambios en esas instancias •

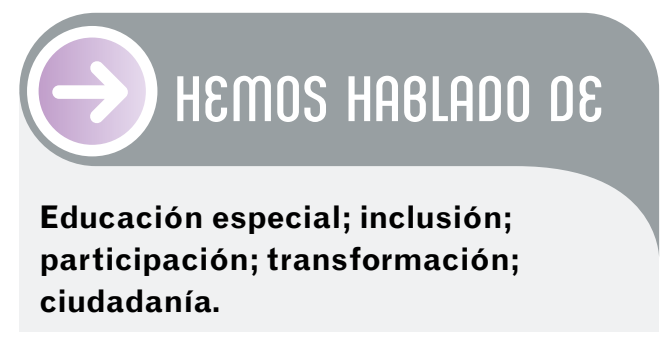

Este artículo fue solicitado por PADRES Y MAESTROS en mayo de 2021, revisado y aceptado en octubre de 2021 